MYU Tokyo

S \& M 1466

\title{
Piezoelectric Thick Film Based on Bonding Technologies for Energy Harvester
}

\author{
Gang Tang, ${ }^{1,2 \dagger}$ Bufeng Bao, ${ }^{2 \dagger}$ Zhiran Yi, $^{2}$ Guimiao Li, ${ }^{2}$ Bin Yang, ${ }^{2 *}$ and Jingquan Liu $^{2}$ \\ ${ }^{1}$ Jiangxi Province Key Laboratory of Precision Drive \& Control, Department of Mechanical and Electrical Engineering, \\ Nanchang Institute of Technology, Nanchang 330099, China \\ ${ }^{2}$ National Key Laboratory of Science and Technology on Micro/Nano Fabrication, \\ Department of Micro/Nano Electronics, Shanghai Jiao Tong University, Shanghai 200240, China
}

(Received August 21, 2017; accepted November 19, 2017)

Keywords: piezoelectric thick film, bonding technologies, piezoelectric energy harvesters

With the development of low-power-consumption electronic devices and systems, the development of power supplies will be a major challenge. High-performance piezoelectric energy harvesters (PEHs) are an alternative that convert mechanical deformation into electric charge. For PEHs, it is highly desirable to utilize materials with a high piezoelectric charge coefficient. Piezoelectric thick films based on bonding and thinning technologies meet this requirement due to their high-temperature sintering process. In this paper we review the development of piezoelectric thick film fabrication processes, including the direct bonding process and the transferring process. Additionally, PEHs in substrates for different applications are described. Moreover, we summarize and compare the output performance of thick-film-based PEHs from all recently published papers in terms of normalized power density and resonant frequency.

\section{Introduction}

With the rapid development of low-power electronics and systems, the development of power supplies for these devices will be a major challenge. However, micro-energy harvesters are an alternative to solve this problem. They convert external mechanical energy into electrical energy by different conversion mechanisms, such as electrostatic, ${ }^{(1-3)}$ electromagnetic, ${ }^{(4-6)}$ triboelectric, ${ }^{(7-9)}$ thermoelectric, ${ }^{(10-12)}$ and piezoelectric ${ }^{(13-16)}$ mechanisms. Because piezoelectric harvesters have a simple structure, a high electromechanical coupling coefficient, no requirement for an external voltage source, and a long lifetime, they have been used in volume-limited wireless sensor nodes. ${ }^{(17)}$ The piezoelectric coefficients of piezoelectric materials affect the output performance of generators. Various piezoelectric materials have been deployed widely in microelectromechanical system (MEMS) energy harvesters, ${ }^{(18-22)}$ such as AlN thin films, piezoelectric ceramic lead zirconate titanate (PZT) thin films, and $\mathrm{ZnO}$ and $\mathrm{BiTO}_{3}$ nanowires. PZT is applied as a functional piezoelectric material in energy harvesters due to its high piezoelectric constant. Many microfabrication processes for PZT thin or thick films for harvesters have been reported. ${ }^{(13,14,23)}$ The common deposition processes for PZT and AlN using sol-gel and sputtering methods limit the thin-film thickness to within 1-2 $\mu \mathrm{m}$. Liu et al. demonstrated a MEMS microgenerator with a $3 \mu \mathrm{m}$ PZT film deposited by the sol-gel process, which generated a power of 19.4-51.3

\footnotetext{
*Corresponding author: e-mail: binyang@sjtu.edu.cn

${ }^{\dagger}$ These authors contributed equally to the work.

http://dx.doi.org/10.18494/SAM.2017.1727
} 
$\mathrm{nW}$ from 30 to $47 \mathrm{~Hz}$ at $1.0 g^{(13)}$ A 1- $\mu$ m-thick PZT film was deposited by spin coating and its structure was analyzed by X-ray diffraction. ${ }^{(14)}$ A $5 \mu \mathrm{m}$ PZT film for $d_{31}$ and $d_{33}$ mode MEMS generators was prepared by an aerosol deposition process. ${ }^{(23)}$ The fabricated device under the $d_{31}$ mode generated a maximum output power of $2.765 \mu \mathrm{W}$ at $255.9 \mathrm{~Hz}$ at an acceleration of $2.5 \mathrm{~g}$. In addition, a hydrothermal method ${ }^{(24)}$ and a screen printing process ${ }^{(25)}$ have been developed for thick films over $5 \mu \mathrm{m}$ in thickness. Lei et al. ${ }^{(26)}$ combined the thick-film screen printing technique and a micromachining process using a silicon on insulator (SOI) wafer to fabricate a microcantilever with a unimorph PZT thick film. The fabricated harvester device produces $14.0 \mu \mathrm{W}$ with an optimal resistive load of $100 \mathrm{k} \Omega$ from $1 \mathrm{~g}$ input acceleration at its resonant frequency of 235 Hz. A sintering temperature above $550{ }^{\circ} \mathrm{C}$ can provide high piezoelectricity, ${ }^{(27)}$ which limits the application of the subsequent MEMS fabrication process. However, bulk PZT ceramics provide higher electromechanical coupling and harvesting efficiency than deposited piezoelectric thin

films. Recently, piezoelectric energy harvesters (PEHs) based on PZT thick films have developed quickly.

In this paper, we review the development of PZT thick-film energy harvesters, including bonding technologies and structural design. Finally, we compare the output performance of all published PZT thick-film harvesters, including the operating conditions, output voltage and power, and normalized power density. This paper will provide some novel routes to improve the output performance of energy harvesters for researchers or engineers in this area.

\section{Bonding Technology of PZT Thick Film}

\subsection{Au as the bonding layer for direct bonding}

In recent years, a useful technique for preparing PZT thick films on silicon has been investigated, namely the wafer bonding of bulk PZT and silicon using an intermediate layer and then using a PZT thinning technique. ${ }^{(28-30)}$ There is no doubt that high-performance bulk PZT may significantly improve the performance of piezoelectric microgenerators. Tanaka et al. ${ }^{(28)}$ prepared PZT thick films by adopting this bonding technology using Au as the intermediate layer and the mechanical lapping method, as shown in Fig. 1(a). The bond strength of polarized $\mathrm{PZT} / \mathrm{Au} / \mathrm{Si}$ wafers for two different poling processes was investigated: (i) the PZT ceramics were polarized by applying $250 \mathrm{~V} \mathrm{DC}\left(0.69 \mathrm{kV} \mathrm{mm}^{-1}\right)$ throughout the entire bonding process [solid lines in Fig. 1(b)]; or (ii) the ceramics were polarized by applying $750 \mathrm{~V} \mathrm{DC}\left(2.1 \mathrm{kV} \mathrm{mm}^{-1}\right)$ only during cooling from $300{ }^{\circ} \mathrm{C}$ to room temperature (dashed line). With the first process, a strength of about $13 \mathrm{MPa}$ was obtained for a wafer bonded at $550{ }^{\circ} \mathrm{C}$ for $1 \mathrm{~h}$ or $450{ }^{\circ} \mathrm{C}$ for $4 \mathrm{~h}$. However, the bonding process needs special fabrication processing and bonding equipment, thus its cost is high. At the same time, because the bonding temperature was higher than $500{ }^{\circ} \mathrm{C}$, some problems appear, such as the repolarization issue and the larger residual stress caused by the thermal mismatch between the PZT ceramics and silicon substrate.

\subsection{Conductive epoxy as the bonding layer for direct bonding}

In order to reduce the fabrication cost of the intermediate layer of $\mathrm{Au}$, the use of epoxy resins as an intermediate layer and a wet-etching process for thinning PZT were demonstrated. ${ }^{(29)}$ Because the epoxy resins used were nonconductive, it was very difficult to expose the bottom electrodes 


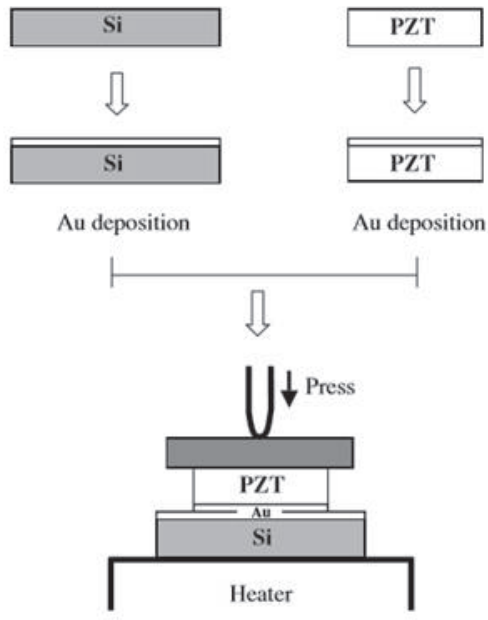

(a)

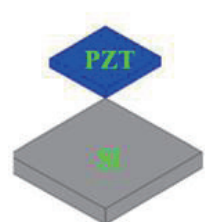

(1)

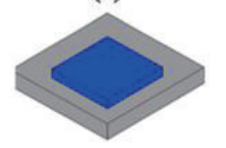

(2)

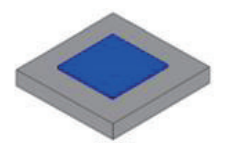

(3)

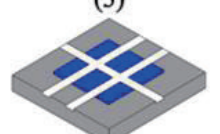

(4)

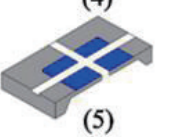

(c)

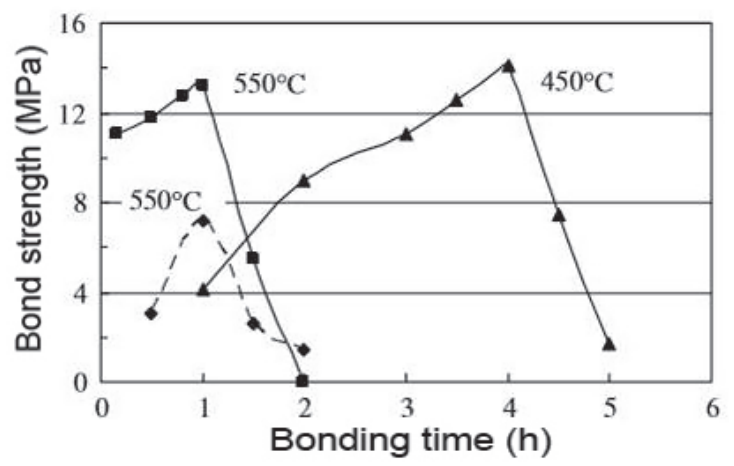

(b)

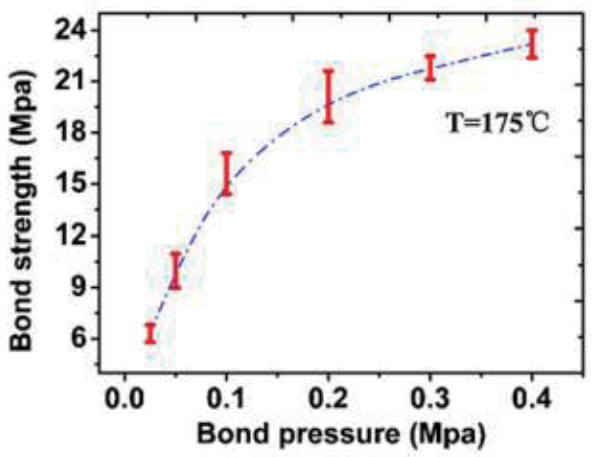

(d)

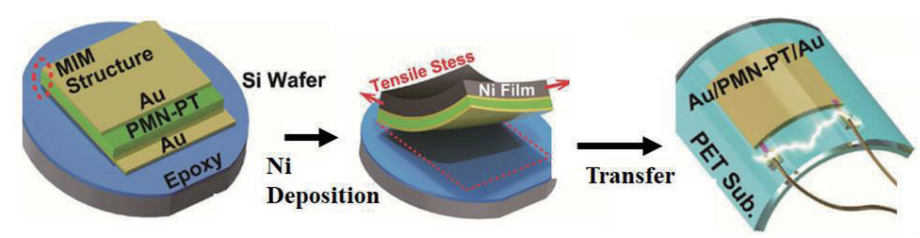

(e)

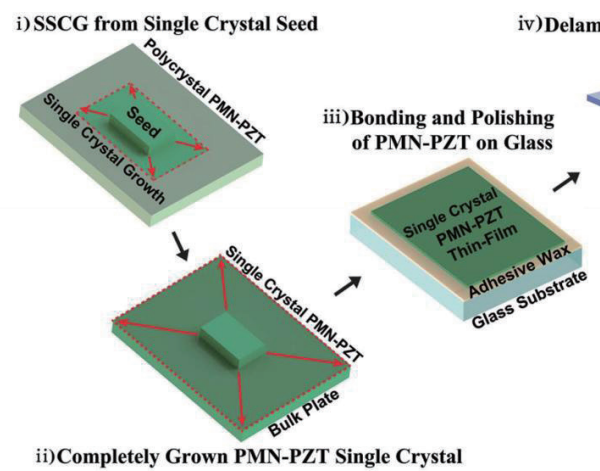

v)Delamination of Piezoelectric Thin Film

(f)

Fig. 1. (Color online) (a) Bonding procedure using Au as bonding layer. (b) Bond strength of polarized PZT$\mathrm{Au}-\mathrm{Si}$ wafers for two different poling processes: poling throughout the entire bonding process (solid lines) and poling during the cooling stage, from $300{ }^{\circ} \mathrm{C}$ to room temperature (dashed line).$^{(28)}$ (c) Bonding process of conductive epoxy. (d) Realized bond strength dependence on the bond pressure at the curing temperature of $175^{\circ} \mathrm{C} .{ }^{(30)}$ (e) Transferring process of PMN-PT thick film. ${ }^{(32)}$ (f) Schematic illustration of the SSCG and fabrication process of the flexible PMN-PZT energy harvester. ${ }^{(38)}$ 
to produce an output signal using the micromachining process. Wang et al. ${ }^{(27)}$ developed the integration of bulk PZT and silicon by Cytop, a patternable bond layer, and the thinning of bulk PZT by the chemical mechanical polishing method.

Bonding processes must ensure the precision of the designed structure. Firstly, a lowtemperature bonding process is essential to reduce the detrimental effect of thermal mismatch between the PZT ceramics and silicon, and to be compatible with subsequent processes. Secondly, the thickness of the intermediate bonding layer should be less than several microns. Thirdly, the thickness uniformity of the intermediate bonding layer should be well controlled in order to reduce the thickness of the bulk PZT and obtain uniformity. Fourthly, the intermediate bonding layer should be conductive. Otherwise, the bottom electrodes will be very difficult to expose. Finally, the bonding strength should be sufficiently high to obtain good reliability of the fabricated device and remain stable under an operating temperature of approximately $150{ }^{\circ} \mathrm{C}$, which is required for later MEMS processes. To satisfy these conditions, Tang et al. ${ }^{(30)}$ proposed a conductive epoxy organic adhesive material as an intermediate bonding layer to bond bulk PZT and silicon wafers at temperatures as low as $175{ }^{\circ} \mathrm{C}$. The conductive epoxy resins (DAD-91L, Shanghai Research Institute of Synthetic Resins) have been used in bonding experiments.

Figure 1(c) shows the bonding process. Firstly, one or two layers of conductive epoxy resin were screen printed on a silicon wafer. Then, the PZT and the silicon wafer were bonded together under a specified pressure and heated at a suitable temperature gradient in a vacuum oven, which was from 60 to $175^{\circ} \mathrm{C}$ at $15^{\circ} \mathrm{C}$ per $10 \mathrm{~min}$, which was followed by holding for more than $1 \mathrm{~h}$ at $175^{\circ} \mathrm{C}$. The temperature gradient and the vacuum oven were necessary to obtain a uniform epoxy layer and remove air bubbles from the bonding layer. The pressure was removed when the temperature reached room temperature after cooling. The etching rate of bulk PZT by the wet-etching method is low and the thickness uniformity of bulk PZT is very difficult to control by a mechanical lapping machine when its thickness is lower than $30 \mu \mathrm{m}$. Therefore, a hybrid method combing the mechanical lapping and wet-etching processes is used to reduce the thickness of the bulk PZT. Several-hundred-micron-thick PZT was thinned to about $30 \mu \mathrm{m}$ using mechanical lapping. Then, a wet-etching process was used to reduce the thickness of the PZT ceramic to the required thickness using 1BHF:2 $\mathrm{HCl}: 4 \mathrm{NH}_{4} \mathrm{Cl}: 4 \mathrm{H}_{2} \mathrm{O}$ as the etchant. ${ }^{(29)}$ Finally, an additional mechanical polishing process was applied on the PZT films to improve the surface roughness of the PZT for subsequent fabrication processes. ${ }^{(29)}$ Figure 1(d) shows the bonding strengths of the PZT-conductive epoxySi-bonded wafers as a function of applied pressure at the curing temperature of $175{ }^{\circ} \mathrm{C}$ during bonding. It can be seen that the bonding strength was more than $10 \mathrm{MPa}$ at an applied pressure of $0.1 \mathrm{MPa}$. The large bond pressure contributed to improving the bond strength. However, the bonded wafers are easily deformed or damaged under higher bond pressure. Therefore, the applied pressure of $0.1 \mathrm{MPa}$ during bonding is a relatively ideal value for use in this application. In addition, the error bar in Fig. 1(d) shows multiple experimental results and good uniformity of bonding strength.

\subsection{Transferring process of piezoelectric thick film}

In order to realize a flexible energy harvester with a high output current, the stress-controlled exfoliating process was proposed to transfer the lead magnesium niobate-lead titanate (PMN-PT) thin film from a bulk substrate onto a flexible substrate without mechanical damage by utilizing the inherent residual stress of a Ni film. ${ }^{(31)}$ Figure $1(\mathrm{e})$ shows the transferring process of a PMN- 
PT thick film. ${ }^{(32)}$ The (001)-oriented PMN-PT crystal was polished to a mirror surface using a diamond suspension. A Au bottom electrode deposited PMN-PT plate was completely bonded on a (100) silicon wafer by adhesive epoxy and then thinned to a film thickness of $8.4 \mu \mathrm{m}$ using grinding and subsequent chemical mechanical polishing (CMP). This mechanical exfoliating process was carried out to peel off the top piezoelectric portion of the PMN-PT metal-insulatormetal (MIM) layer ( $8.6 \mu \mathrm{m}$ in thickness) from the silicon substrate using an electroplated tensile $\mathrm{Ni}$ stressor. The directional stress mismatch between the top Ni film (intrinsic tensile stress) and the underlying layers (against compressive stress) of the MIM/epoxy/wafer released the piezoelectric thin film from the mother substrate without mechanical damage such as cracking, delamination, or wrinkling. ${ }^{(31)}$ Moreover, the thickness of the exfoliated PMN-PT can be easily controlled by modulating the residual stress of the Ni film. ${ }^{(33)}$ The freestanding thin PMN-PT film on a thin plastic substrate was sufficiently flexible to conform to achieve conformal contact on a curved subcutaneous layer and corrugated organs in the human body, thus making it possible to generate energy in the human body by slight mechanical movements. ${ }^{(34)}$

Meanwhile, in order to enhance the conversion efficiency of energy harvesters, researchers have demonstrated an inherently high-piezoelectric-coefficient perovskite thin film on a plastic substrate using a soft-lithographic transfer technique, enabling high-quality thin-film materials on a flexible substrate. ${ }^{(35-37)}$ Figure 1(f) schematically illustrates the solid-state single crystal growth (SSCG) of lead magnesium niobate-lead zirconate titanate (PMN-PZT) and flexible device fabrication. ${ }^{(38)}$ The single-crystal PMN-PZT block was completely bonded on a glass substrate using an adhesive wax with a melting temperature of $60{ }^{\circ} \mathrm{C}$. The PMN-PZT bulk on glass was thinned to a film thickness of $10 \mu \mathrm{m}$ via a polishing process. The PMN-PZT thin film (area of $2 \times 3 \mathrm{~cm}^{2}$ ) on the glass substrate was placed on a polyethylene terephthalate (PET; thickness, $125 \mu \mathrm{m}$ ) receiver substrate coated with ultraviolet (UV)-sensitive polyurethane (PU; Norland optical adhesive, No. 73) as an adhesive epoxy and then UV light was used to cure the PU adhesive. The sample was heated on a hot plate at the melting temperature of the adhesive wax to separate the entire area of the PMN-PZT thin film from the glass. Park et al. demonstrated large-area PZT thin films on flexible substrates via a laser lift-off (LLO) process and fabricated a thin-film nanogenerator (NG) to realize highly efficient, lightweight, and flexible piezoelectric energy harvesting devices. ${ }^{(39)}$

\section{3. $\quad$ PZT Thick Film Based Energy Harvesters}

\subsection{Silicon-based energy harvesters}

Aktakka et al. ${ }^{(40)}$ fabricated a unimorph piezoelectric cantilever with a thinned-PZT layer of $20 \mu \mathrm{m}$ thickness for vibration energy harvesting. The bulk-PZT pieces were bonded to an SOI wafer using an $\mathrm{Au} / \mathrm{In}$ bonding layer of $5 \mu \mathrm{m}$ thickness and were later thinned to about $20 \mu \mathrm{m}$. The unpackaged harvester with a tungsten proof mass produces a maximum power of $2.74 \mu \mathrm{W}$ at $0.1 \mathrm{~g}(167$ $\mathrm{Hz})$ and $205 \mu \mathrm{W}$ at $1.5 \mathrm{~g}(154 \mathrm{~Hz})$ at resonance.

Recently, a novel process to fabricate low-frequency piezoelectric MEMS energy harvesters by bonding bulk PZT on an SOI structure was proposed by Tang et al. ${ }^{(30)}$ The key techniques of the process include a low-temperature bonding technique using conductive epoxy resin, thinning of the bulk PZT using a combined mechanical lapping and wet-etching method, and the micromachining of bulk ceramics by dicing. As shown in Fig. 2(a), a unimorph PZT microcantilever array constructed with $\mathrm{Au} / \mathrm{Cr} / \mathrm{PZT} /$ conductive epoxy $/ \mathrm{Cr} / \mathrm{Au} / \mathrm{SiO}_{2} / \mathrm{Si} / \mathrm{SiO}_{2}$ multilayer structure with a Ni proof mass 

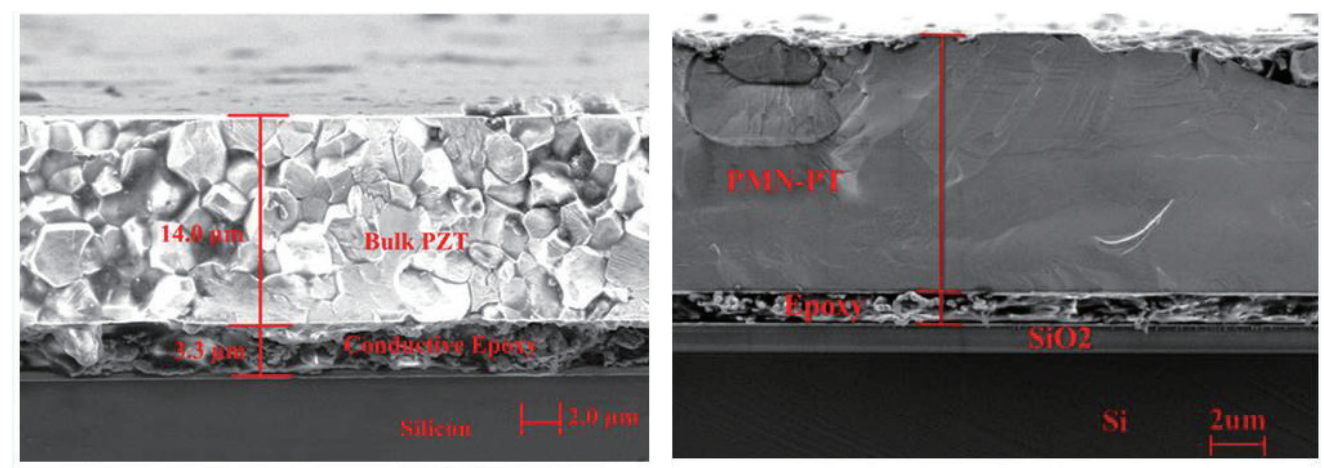

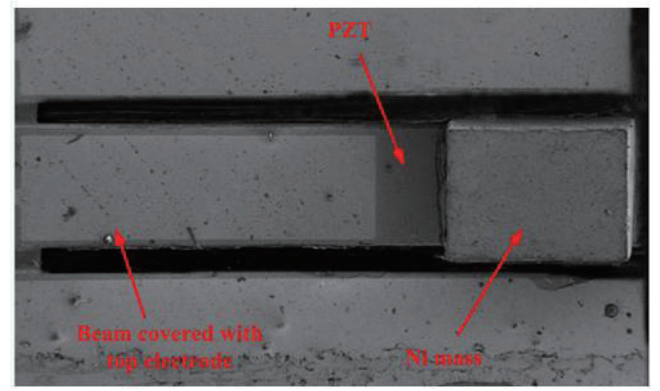

(a)

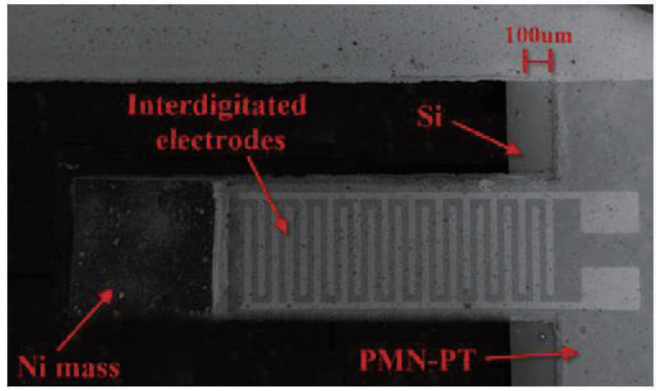

(b)
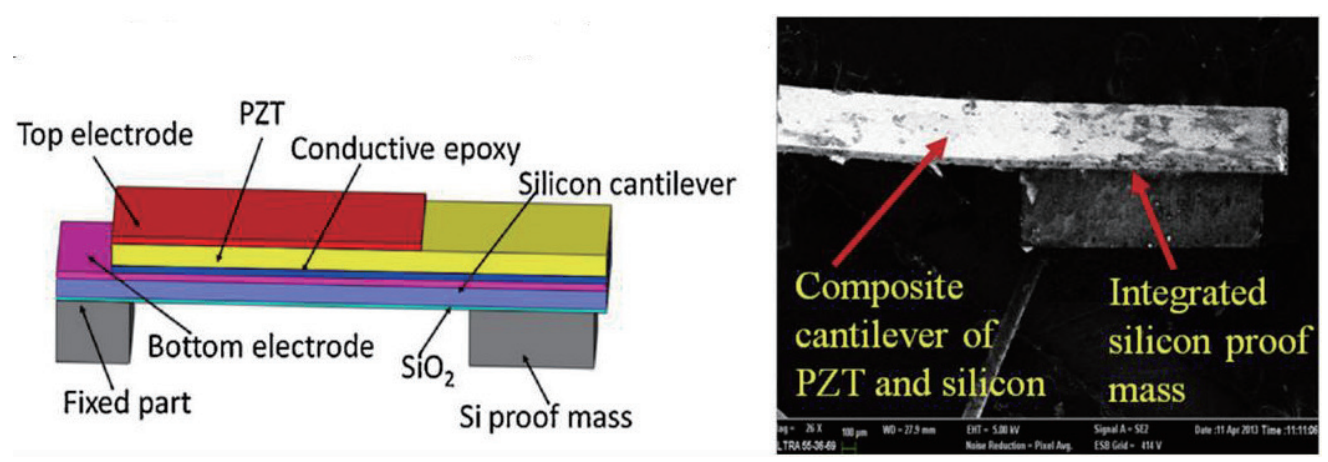

(c)

Fig. 2. (Color online) SEM cross-section view and top view of the fabricated (a) 31-mode thick PZT microcantilever, ${ }^{(30)}$ (b) 33-mode thick PMN-PT microcantilever, ${ }^{(41)}$ and (c) 31-mode PZT harvester with integrated proof mass. $^{(42)}$

was designed and fabricated. With an exicitation of $1.0 \mathrm{~g}$, the output voltage, power, and power density of this device are $2.72 \mathrm{~V}_{\mathrm{P}-\mathrm{P}}, 11.56 \mu \mathrm{W}$, and $28856.7 \mu \mathrm{W} \mathrm{cm}{ }^{-3}$ at the resonant frequency of $514.1 \mathrm{~Hz}$ with a matched load resistance of $70 \mathrm{k} \Omega$. The output performance of this device is higher than that of other reported MEMS devices using piezoelectric thin films. Therefore, this novel technique has great potential to allow the fabrication of high-performance piezoelectric MEMS energy harvesters. Using this fabrication technique, we have developed a high-performance piezoelectric 33-mode MEMS energy harvester based on PMN-PT single-crystal thick film as shown in Fig. 2(b). ${ }^{(41)}$ The PMN-PT piezoelectric thick film is used to improve the coupling coefficient and electromechanical coefficient. Interdigitated electrodes (IDEs) contribute to the improved energy conversion efficiency of the 33 -mode harvester. The experimental results show 
that the fabricated microcantilever produced a maximum output voltage and power of $5.36 \mathrm{~V}_{\mathrm{P}-\mathrm{P}}$ and $7.182 \mu \mathrm{W}$, respectively, at the resonant frequency of $406 \mathrm{~Hz}$. The calculated power density of $17181.8 \mu \mathrm{W} / \mathrm{cm}^{3}$ is also very promising compared with other reported devices.

In the above-reported studies, the $\mathrm{Ni}$ proof mass was manually assembled at the tip of the cantilever, which resulted in the mismatch of the locations of the centers of the cantilever and proof mass. As a result, the cantilever will twist under deformation. Therefore, the output performance and conformance will be reduced. We proposed a high-performance vibration-based energy harvester with an integrated silicon proof mass, as shown in Fig. 2(c), which was formed by the deep reactive-ion etching (DRIE) process from the opposite side. ${ }^{(42)}$ The maximum output voltage and power of our device at the resonant frequency are $3.4 \mathrm{~V}$ and $20.2 \mu \mathrm{W}$, and $6.08 \mathrm{~V}$ and $57.6 \mu \mathrm{W}$ under input vibration accelerations of $0.5 \mathrm{~g}$ and $1 \mathrm{~g}$, respectively. The power density of the harvester under $0.5 g$ and $1 g$ is 24754.9 and $70588.2 \mu \mathrm{W} / \mathrm{cm}^{3}$, respectively. The energy conversion efficiency of the harvester at $0.5 g$ and $1 g$ is $38.15 \%$ and $26.9 \%$, respectively.

\subsection{Flexible-metal-foil-based energy harvesters}

Most of the above-reported PEHs based on silicon technology easily break down and only work at low vibration levels from ambient sources due to the brittle properties of silicon. Currently, most reported high-performance PEHs operate at high frequencies. However, the frequencies of environmental vibration sources are relatively low (normally less than $100 \mathrm{~Hz}$ ). ${ }^{(43)}$ Although fewer papers have reported low-frequency PEHs, they worked below 2.0g, and their output power was very low. However, in the fields of aerospace and the military, the acceleration of a ballistic missile or rocket during launch can reach from $4 g$ to $15 g$. Meanwhile, in a domestic environment, the acceleration of automobiles and hand tools can also reach $10.0 g^{(44-48)}$ Phosphor bronze, an alloy of copper, has good electrical conductivity and resistance to fatigue, so phosphor bronze can replace silicon as the substrate of energy harvesters operating at low frequency and high vibration levels. Therefore, we have developed a piezoelectric microgenerator based on bulk PZT bonding on the phosphor bronze composite structure to convert vibration energy into electricity. ${ }^{(49)}$ Figure 3 illustrates the fabrication process of the microgenerator. The whole structure includes phosphor bronze as the supporting layer, a bulk PZT thin film as the functional piezoelectric layer, conductive epoxy as the low-temperature bonding layer, and a proof mass. The starting wafer of $400-\mu \mathrm{m}$-thick silicon has a $2-\mu \mathrm{m}$ silicon oxide layer that is used to bond with $100-\mu \mathrm{m}$ thick phosphor bronze, as shown in Fig. 3(a). The phosphor bronze should be thinned to the appropriate thickness to reduce the resonant frequency and the top surface should be polished to improve the bonding force with the bulk PZT [Fig. 3(b)]. Then, one side of the 400- $\mu \mathrm{m}$-thick PZT is polished and deposited with the $20 \mathrm{~nm} / 180 \mathrm{~nm} \mathrm{Cr} / \mathrm{Au}$ bottom electrode layer. This side of the bulk PZT is bonded to the phosphor bronze with epoxy resin [Fig. 3(c)]. The PZT layer is thinned down to the required thickness [Fig. 3(d)] by the combined mechanical lapping and wet-etching method. Figures 3(e) and 3(f) illustrate the $\mathrm{Cr} / \mathrm{Au}$ layer as the top electrode, which was sputtered and patterned by dry etching to form the top and bottom electrodes, respectively. Figure $3(\mathrm{~g})$ shows that the handle Si layer was etched from underneath to release the cantilever with a silicon proof mass by the DRIE process. Finally, Fig. 3(h) shows the rectangular tungsten proof mass cut by the dicing method is assembled at the end of the cantilever. Due to the elasticity and fatigue resistance effects of the phosphor bronze, the device can withstand a vibration acceleration of $7.0 \mathrm{~g}$ 
(a)

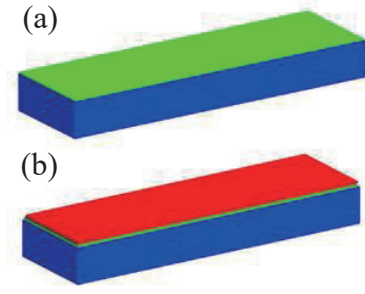

(c)

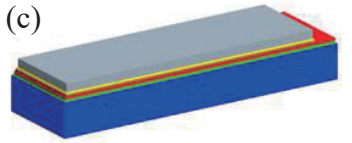

(d)

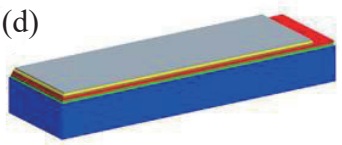

(e)

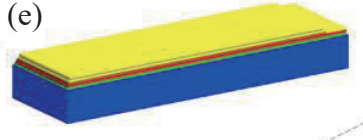

(f)

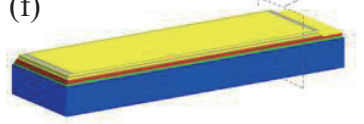

(g)

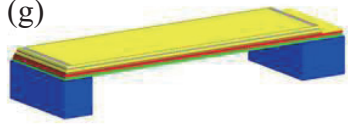

(h)

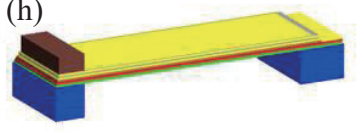

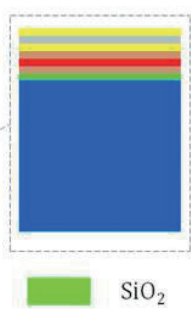

Silicon

Phosphor bronze

PZT

Epoxy

$\mathrm{Au}$

Tungsten mass

Fig. 3. (Color online) Fabrication process of microgenerator. (a) Silicon oxide deposited on silicon wafer. (b) Bonding phosphor bronze and silicon wafer and thinning of the phosphor bronze by mechanical lapping. (c) Bulk PZT with bottom electrode bonding with phosphor bronze. (d) Thinning of PZT by using the combined mechanical lapping and wet-etching method and polishing. (e) Top electrode deposition. (f) Top electrode patterning. (g) Underside etching by DRIE. (h) Tungsten mass assembled at the end of the cantilever. ${ }^{(49)}$

and generate an output voltage of $61.2 \mathrm{~V}$. Figure 4(a) shows the output voltage at different loading resistances under different accelerations from $0.5 \mathrm{~g}$ to $3.0 \mathrm{~g}$. The effective volume of the fabricated microgenerator is calculated as $0.03732 \mathrm{~cm}^{3}$, and as the acceleration was increased from $0.5 \mathrm{~g}$ to $3.0 \mathrm{~g}$, the power density increased 24.7 times, from 351.02 to $8664 \mu \mathrm{W} \cdot \mathrm{cm}^{-3}$, as shown in Fig. 4(b).

\subsection{Energy harvesters with flexible polymer substrate}

A flexible and lightweight energy harvester on a single thin plastic substrate can scavenge energy from extremely small movements into electric signals. ${ }^{(50,51)}$ Hwang et al. reported a flexible energy harvester based on a PMN-PT thick film on a plastic substrate that can significantly increase output current. ${ }^{(32)}$ Figure 5(a) shows the flexible PMN-PT energy harvester being bent by tweezers without notable damage, and the inset shows the device on a rounded glass vial with a curvature radius of $1.4 \mathrm{~cm}$. Periodic bending/unbending of this harvester was performed by a linear motor with a strain of $0.36 \%$ at a strain rate of $2.3 \% \cdot \mathrm{s}^{-1}$ (frequency of $0.3 \mathrm{~Hz}$ ) to evaluate the output performance of this device. The output voltage and current are shown in Figs. 5(b)(i) and 5(b)(ii), respectively. The maximum voltage and rectified current were about $8 \mathrm{~V}$ and $100 \mu \mathrm{A}$, respectively. Fifty parallel-connected green LEDs were lighted simultaneously with the generated electric power. In addition, the same group proposed a large-area $d_{33}$-mode PZT energy harvester fabricated via a laser lift-off process, which is shown in Fig. 5 (c). ${ }^{(39)}$ Figure 5(d)(i) shows the open-circuit voltage of $200 \mathrm{~V}$ and the short-circuit current of $1.5 \mu \mathrm{A}$ at a strain of $\sim 0.386 \%$ with a strain rate of $2.32 \% \mathrm{~s}^{-1}$. To characterize the effective power outputs of the PZT harvester, the voltage and current density signals were recorded as a function of loading resistance from $2 \mathrm{k} \Omega$ to $1 \mathrm{G} \Omega$ [Fig. 5(d)(ii)]. As a result, the instantaneous power density can be calculated by multiplying the output voltage and current, reaching up to $17.5 \mathrm{~mW} \cdot \mathrm{cm}^{-2}$ at a resistance of $200 \mathrm{M} \Omega$. 


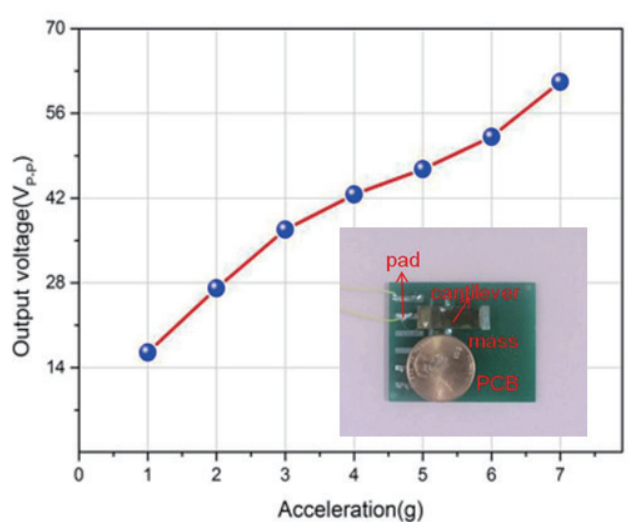

(a)

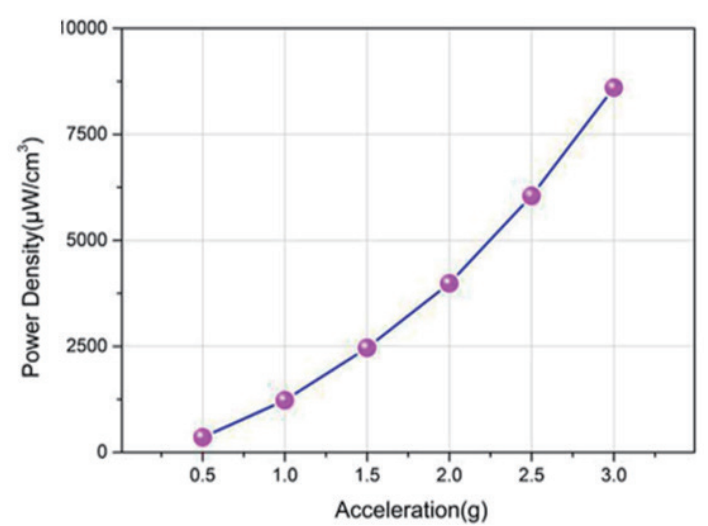

(b)

Fig. 4. (Color online) (a) Open-circuit output voltage from $1 g$ to $7 g$ at resonant frequency. (b) The power density from $0.5 \mathrm{~g}$ to $3.0 \mathrm{~g}$ at resonant frequency. ${ }^{(49)}$

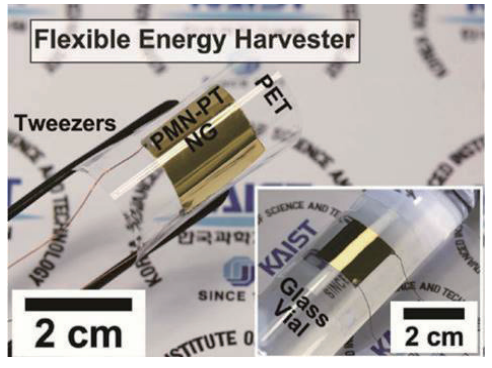

(a)

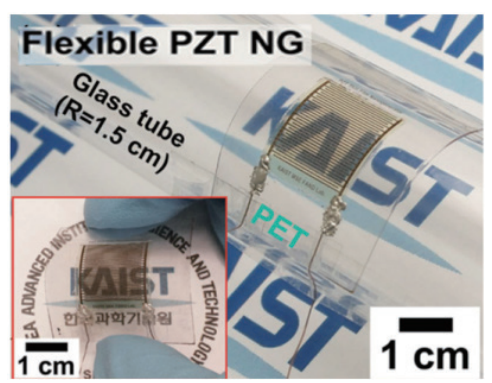

(c)

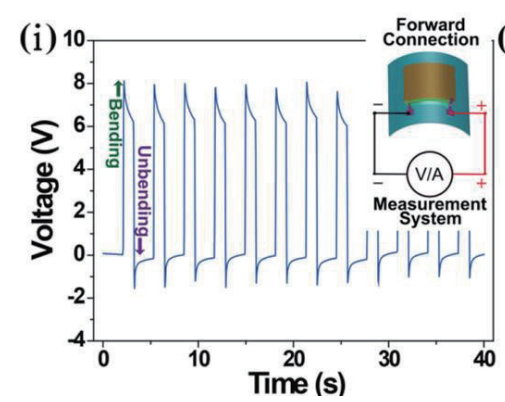

(b)
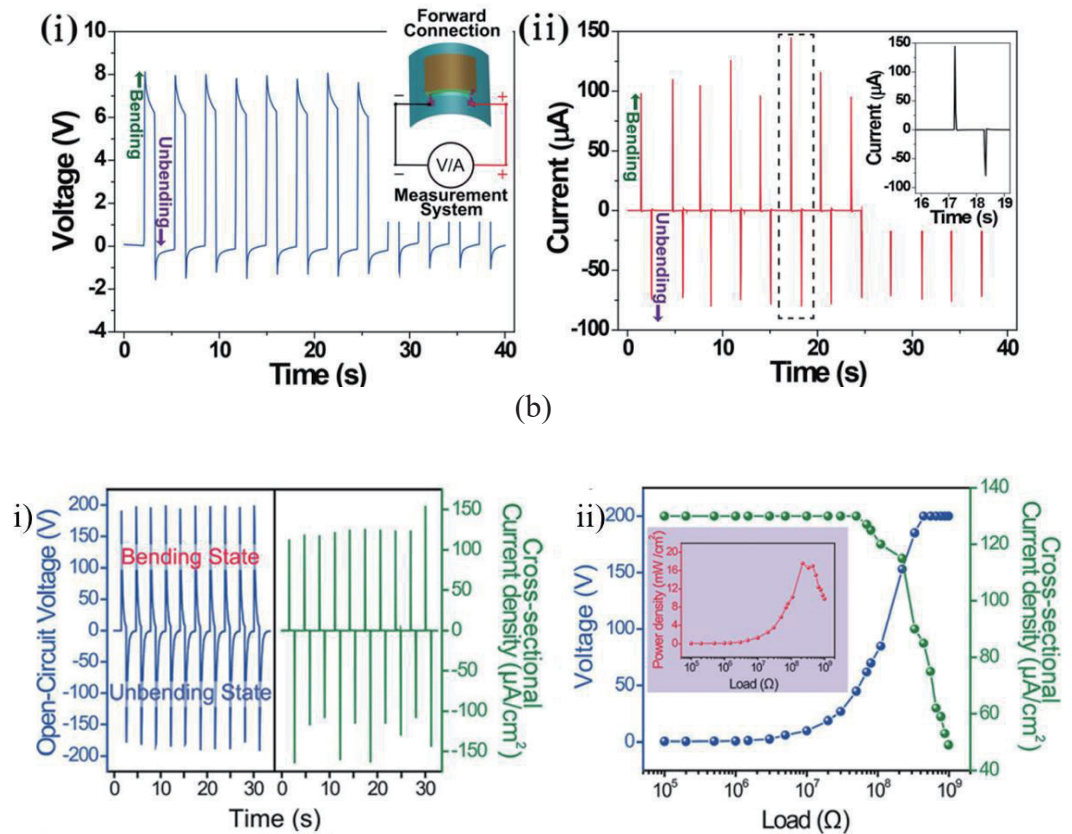

(d)

Fig. 5. (Color online) (a) Photograph of flexible PMN-PT thin-film energy harvester on a PET substrate. (b) Open-circuit voltage (i) and short-circuit current (ii) signals generated from the energy harvester during periodic bending and unbending. ${ }^{(32)}$ (c) Final flexible PZT thin-film NG attached to a glass tube and bent by human fingers (inset) (d) (i) Open-circuit voltage and cross-sectional current density measured from PZT thin-film NG and (ii) Measured output voltage and cross-sectional current density under different load resistances from $2 \mathrm{k} \Omega$ to $1 \mathrm{G} \Omega$. $^{(39)}$

A Mn-doped PMN-PZT crystal has a high piezoelectric charge coefficient $\left(d_{33} \approx 1140\right.$ $\left.\mathrm{pC} \mathrm{N}^{-1}\right)^{(52,53)}$ and electromechanical coupling factor $\left(k_{33} \approx 0.92\right)$, which are significantly greater than those of other PZT materials. ${ }^{(52)}$ Kim et al. demonstrated a flexible single-crystalline $(1-x) \mathrm{Pb}\left(\mathrm{Mg}_{1 / 3} \mathrm{Nb}_{2 / 3}\right) \mathrm{O}_{3}-(x) \mathrm{Pb}(\mathrm{Zr}, \mathrm{Ti}) \mathrm{O}_{3}$ with $0.5 \mathrm{~mol} \% \mathrm{Mn}$ doping energy harvester for scavenging 
in vivo biomechanical energy. ${ }^{(54)}$ This single-crystal harvester generated a short-circuit current of 1.75 $\mu \mathrm{A}$ and an open-circuit voltage of $17.8 \mathrm{~V}$. It was able to switch a light bulb on and off at a distance of approximately $5 \mathrm{~m}$ without requiring any other power source.

\subsection{Bimorph PEHs (B-PEHs)}

Yeo et al. presented a high-efficiency bimorph PEH with a piezoelectric compliant mechanism design via depositing PZT films on Ni foils based on RF magnetron sputtering. ${ }^{(55)}$ We have fabricated a B-PEH based on bulk PZT thick films with a low resonant frequency over a wide range of acceleration, which was realized by utilizing low-temperature bonding and thinning technology on flexible beryllium bronze substrates at a low cost. ${ }^{(56)}$ Figure 6(a) illustrates the threedimensional structure and micromachining process of B-PEH. The structure includes beryllium bronze as a supporting layer, upper and lower bulk PZT thick films as functional piezoelectric layers, conductive epoxy as a low-temperature bonding layer, and a proof mass. The effective volume of this device was $30.6 \mathrm{~mm}^{3}$. Polymethyl methacrylate was utilized for the package of this device, which is shown in Fig. 6(b). The impedance of the fabricated piezoelectric harvester was measured using an impedance analyzer (Keysight 4990A). The results are shown in Fig. 6(c), and show the optimal resistive load to be $325 \mathrm{k} \Omega$. The upper and lower PZT layers were thinned down to about 53 and $76 \mu \mathrm{m}$, respectively, and commercial beryllium bronze with a thickness of approximately $50 \mu \mathrm{m}$ was used as the substrate, as shown in Fig. 6(d). Figure 6(e) shows that the maximum effective output powers generated from the upper, lower, and bimorph beams at $3.0 \mathrm{~g}$ were around $0.563,0.396$, and $0.741 \mathrm{~mW}$ at matched load resistances of around 200, 120, and 360 $\mathrm{k} \Omega$, respectively at $3.0 \mathrm{~g}$. The harvester can light up about twenty-one serial LEDs at resonance under an applied acceleration amplitude of $3.0 \mathrm{~g}$. The output power increased in a manner similar to a quadratic curve, which followed the general model of a velocity-damped oscillator for the conversion of mechanical energy of the vibrating mass into electrical power. ${ }^{(57,58)}$

We have summarized the development of PEHs in recent years, as shown in Fig. 7. It can be observed that the designed resonant frequency of harvesters has decreased to meet the natural frequency of environmental vibration sources. Meanwhile, because the silicon substrate is brittle and cannot work at high accelerations, the flexible copper foil has been selected as the bonding substrate. It is clear that the bimorph energy harvester has improved the normalized power density.

\section{Performance Comparison of Piezoelectric Thick Film Energy Harvesters}

A variety of PEHs based on PZT thick films have been developed and their affected factors are different. In order to compare their output performance, the input conditions including substrate materials, volume, and vibration acceleration, and the output performance including the resonant frequency, power density, and normalized power density are given in detail in Table 1. The earliest developed energy harvester utilized a steel substrate and bulk PZT-5A bimorph in 2004. However, the volume (about $494 \mathrm{~mm}^{3}$ ) was very large. To reduce the device volume, some micromachining methods were proposed for the fabrication of energy harvesters, including the thinned bulk PZT and micropatterning methods. Because silicon is easy to fabricate, some developed energy harvesters are micromachined on silicon substrates.

However, the resonant frequency of silicon-based energy harvesters is very high, which results in high resonant frequencies larger than $150 \mathrm{~Hz}$. However, the frequencies of environmental 


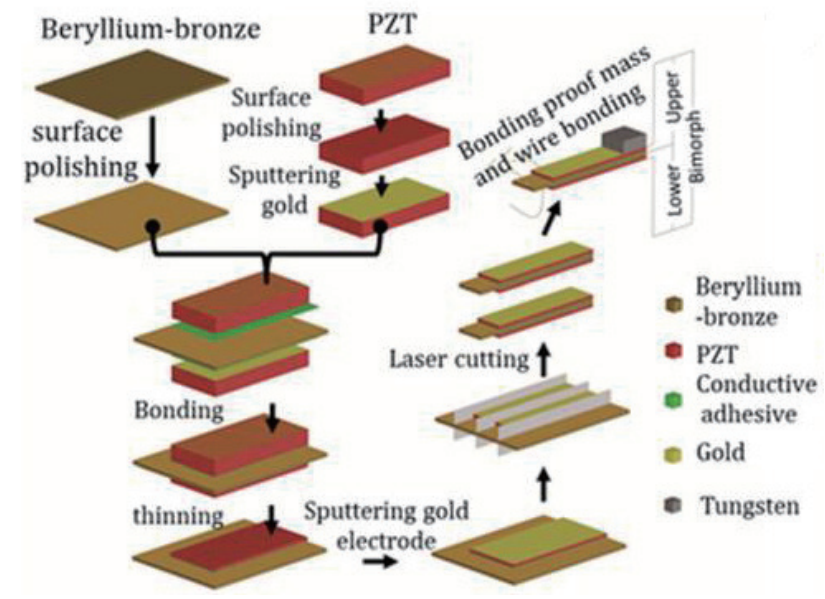

(a)

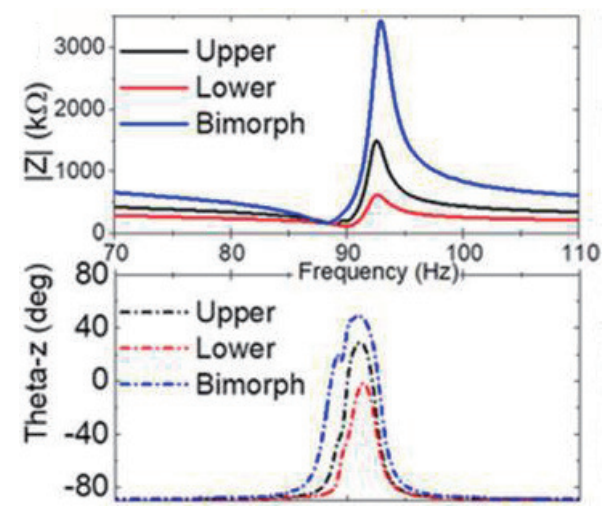

(c)

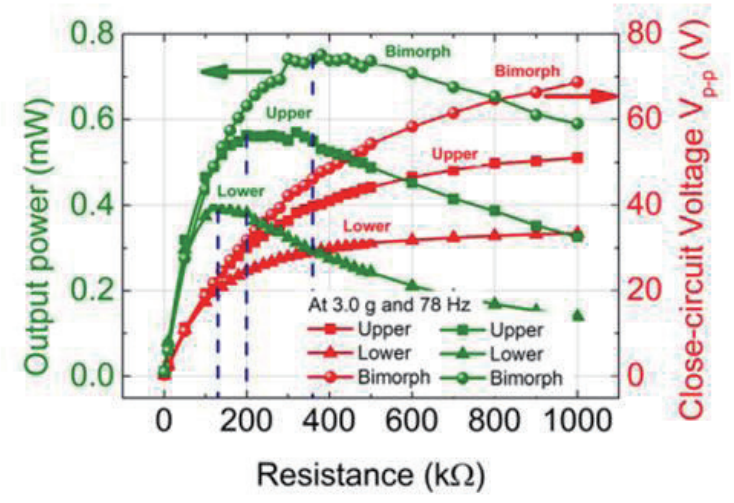

(e)

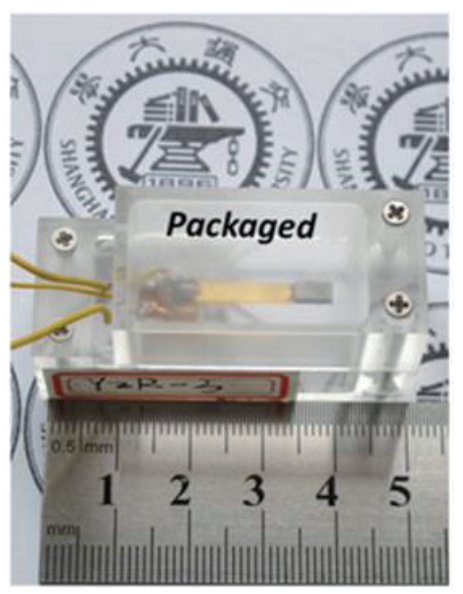

(b)

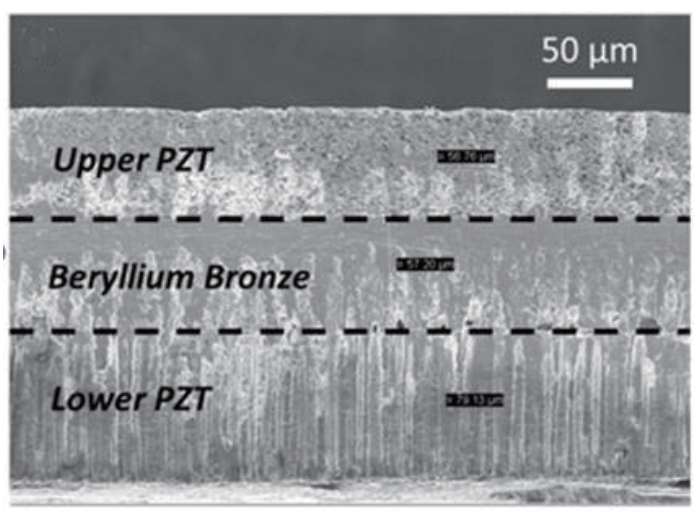

(d)

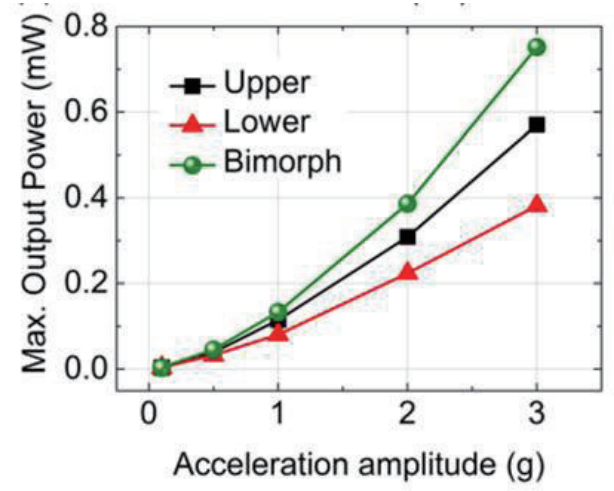

(f)

Fig. 6. (Color online) (a) Schematic illustration of the micromachining processes of the proposed B-PEH. (b) Photograph of the packaged device. (c) Impedance spectrum of the device measured under the free condition. (d) Cross-sectional SEM image of the bimorph PZT layer. (e) Output voltage (red) and power (green) as a function of external load resistances for upper, lower, and bimorph PZT layers of the piezoelectric harvester. Label colors correspond to the inner color. (f) Maximum output power versus acceleration amplitude. ${ }^{(56)}$ 


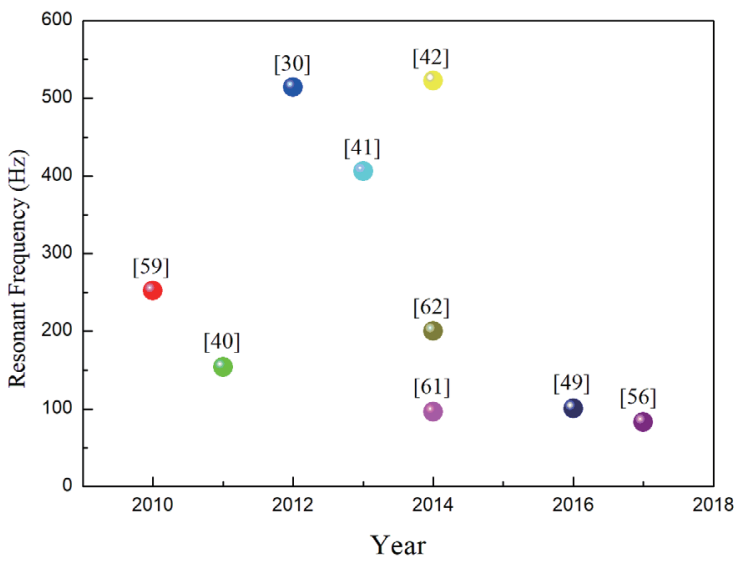

(a)

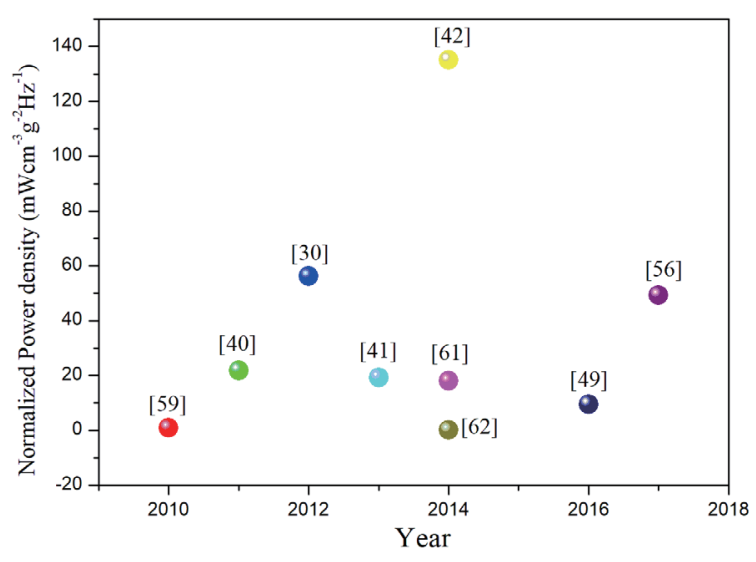

(b)

Fig. 7. (Color online) Development of energy harvesters in recent years.

Table 1

Output performance of recent PEHs based on piezoelectric thick films.

\begin{tabular}{|c|c|c|c|c|c|c|c|c|}
\hline Authors & $\begin{array}{l}\text { Piezoelectric } \\
\text { material }\end{array}$ & $\begin{array}{l}\text { Supporting } \\
\text { material }\end{array}$ & $\begin{array}{l}\text { Volume } \\
\left(\mathrm{mm}^{3}\right)\end{array}$ & $\begin{array}{l}\text { Power } \\
(\mu \mathrm{W})\end{array}$ & $\begin{array}{c}\text { Acceleration } \\
(g)\end{array}$ & $\begin{array}{l}\text { Frequency } \\
\qquad(\mathrm{Hz})\end{array}$ & $\begin{array}{l}\text { Power density } \\
\left(\mu \mathrm{W} \cdot \mathrm{mm}^{-3}\right)\end{array}$ & $\begin{array}{c}\text { Normalized } \\
\text { power density } \\
\left(\mu \mathrm{W} \cdot \mathrm{mm}^{-3} \mathrm{~g}^{-2} \mathrm{~Hz}^{-1}\right)\end{array}$ \\
\hline $\begin{array}{l}2004 \\
\text { Roundy et al. }\end{array}$ & $\begin{array}{l}\text { Bulk PZT-5A } \\
\text { bimorph }\end{array}$ & Steel & 494.472 & 375 & 0.255 & 120 & 0.758385 & 0.097191 \\
\hline $\begin{array}{l}2010 \\
\text { Aktakka et al. }\end{array}$ & Bulk PZT & AuIn & 12.1 & 10.2 & 2.0 & 252 & 0.842975 & 0.000836 \\
\hline $\begin{array}{l}2011 \\
\text { Reilly et al. }{ }^{(60)}\end{array}$ & Bulk PZT-5H & Brass & 613 & 4000 & 0.25 & 100 & 6.525285 & 1.044046 \\
\hline $\begin{array}{l}2011 \\
\text { Aktakka et al. }\end{array}$ & $\begin{array}{l}\text { Thinned } \\
\text { bulk PZT }\end{array}$ & Silicon & 27 & 205 & 1.5 & 154 & 7.592593 & 0.021912 \\
\hline $\begin{array}{l}2012 \\
\text { Tang et al. }\end{array}$ & $\begin{array}{l}\text { Thinned } \\
\text { bulk PZT }\end{array}$ & Silicon & 0.4 & 11.56 & 1.0 & 514.1 & 28.9 & 0.056215 \\
\hline $\begin{array}{l}2013 \\
\text { Tang et al. }\end{array}$ & $\begin{array}{c}\text { Thinned } \\
\text { bulk PMN-PT }\end{array}$ & Silicon & 0.407 & 7.182 & 1.5 & 406 & 17.64619 & 0.019317 \\
\hline $\begin{array}{l}2014 \\
\text { Janphuang et al. }\end{array}$ & $\begin{array}{c}\text { Thinned } \\
\text { bulk PZT }\end{array}$ & Silicon & 47.82 & 82.4 & 1.0 & 96 & 1.723128 & 0.017949 \\
\hline $\begin{array}{l}2014 \\
\text { Yang et al. }{ }^{(42)}\end{array}$ & $\begin{array}{c}\text { Thinned } \\
\text { bulk PZT }\end{array}$ & Silicon & 0.816 & 57.6 & 1.0 & 523 & 70.58824 & 0.134968 \\
\hline $\begin{array}{l}2014 \\
\text { Yang et al. }\end{array}$ & $\begin{array}{c}\text { Thinned } \\
\text { bulk PMN-PT }\end{array}$ & Silicon & 1.24 & 0.139 & 2.0 & 200 & 0.112097 & 0.00014 \\
\hline $\begin{array}{l}2016 \\
\text { Tang et al. }\end{array}$ & $\begin{array}{c}\text { Thinned } \\
\text { bulk PZT }\end{array}$ & $\begin{array}{l}\text { Phosphor } \\
\text { bronze }\end{array}$ & 37.05 & 321 & 3.0 & 100.8 & 8.663968 & 0.00955 \\
\hline 2017 & Thinned & Beryllium & 306 & 979 & 3.5 & 77.2 & 31.99346405 & 0.033830458 \\
\hline Yi et al. ${ }^{(56)}$ & bulk PZT & bronze & 30.6 & 125.2 & 1.0 & 83 & 4.091503268 & 0.04929522 \\
\hline
\end{tabular}

vibration sources are relatively low (normally less than $200 \mathrm{~Hz}$ ). For example, a small microwave oven works at a resonant frequency of $121 \mathrm{~Hz}$, a washing machine at $109 \mathrm{~Hz}$, a kitchen blender casing at $121 \mathrm{~Hz}$, and a CD on notebook computer at $75 \mathrm{~Hz} .{ }^{(49)}$ Meanwhile, silicon is brittle and 
cannot withstand high acceleration. Phosphor and beryllium bronze, as alloys of copper, have good electrical conductivity and resistance to fatigue, so phosphor bronze can replace silicon as the substrate of energy harvesters operating at low frequencies and high vibration levels. In 2016 and 2017, phosphor and beryllium bronze-based energy harvesters operated at resonant frequencies of 100.8 and $77.2 \mathrm{~Hz}$, respectively.

Because the output power is not only related with the volume, but also the resonant frequency and input vibration conditions, the normalized power density is very useful for comparing energy harvester output performance. As can be seen in Table 1, the aforementioned bulk PZT bonding and thinning technique can increase the output power. But it is very difficult to obtain large normalized power density at low frequencies. In future, improving the power density will be a research hotspot for the application of energy harvesters.

\section{Conclusions}

High-performance PEHs are a power supply option for wireless electronics. It is highly desirable to utilize materials with a high piezoelectric charge coefficient for PEHs. Bulk PZT ceramic is a good choice due to its higher electro-mechanical coupling coefficient and higher conversion efficiency (the ratio between the output electrical energy and the input mechanical energy) than deposited piezoelectric films such as AlN or sol-gel PZT. Piezoelectric thick films based on bonding and thinning bulk PZT technologies will realize high-performance PEHs. In this manuscript, the development of piezoelectric thick-film fabrication processes including the direct bonding process and the transfer process has been reviewed. PEHs on silicon, flexible metal foil, and flexible polymer substrates have been described and their applications considered on the basis of their working conditions. Finally, the output performance of thick-film-based PEHs from all published papers was compared in terms of the materials, working conditions, power density, and normalized power density. This will give some design routes for researchers or engineers in this area.

\section{Acknowledgments}

This work was supported by the National Natural Science Foundation of China (51565038) the Open Fund of Jiangxi Province Key Laboratory of Precision Drive \& Control (PLPDC-KFKT-201603), and the 863 Program (2015AA043503).

\section{References}

1 P. D. Mitcheson, P. Miao, B. H. Stark, E. M. Yeatman, A. S. Holmes, and T. C. Green: Sens. Actuators, A 115 (2004) 523.

2 I. Kuehne, A. Frey, D. Marinkovic, G. Eckstein, and H. Seidel: Sens. Actuators, A 142 (2008) 263.

3 B. Yang, C. K. Lee, R. K. Kotlanka, J. Xie, and S. P. Lim: J. Micromech. Microeng. 20 (2010) 065017.

4 I. Sari, T. Balkan, and H. Kulah: Sens. Actuators, A 145 (2008) 405.

5 B. Yang, C. K. Lee, W. F. Xiang, J. Xie, H. He, R. K. Kotlanka, S. P. Low, and H. H. Feng: J. Micromech. Microeng. 19 (2009) 035001.

6 I. Sari, T. Balkan, and H. Kulah: J. Micromech. Microeng. 19 (2009) 105023.

7 Y. B. Zhu, B. Yang, J. Q. Liu, X. Z. Wang, L. X. Wang, X. Chen, and C. S. Yang: Sci. Rep. 6 (2016) 22233.

8 L. Dhakar, F. E. H. Tay, and C. K. Lee: J. Microelectromech. Syst. 24 (2015) 91.

9 Y. B. Zhu, B. Yang, J. Liu, X. Wang, X. Chen, and C. Yang: J. Microelectromech. Syst. 6 (2015) 513. 
10 G. Min and D. Rowe: IEEE Trans. Energy Conver. 22 (2007)528.

11 J. Xie, C. Lee, M. Wang,Y. Liu, and H. Feng: J. Micromech. Microeng. 19 (2009) 125029.

12 W. Glatz, S. Muntwyler, and C. Hierold: Sens. Actuators, A 132 (2006) 337.

13 H. C. Liu, C. J. Tay, C. G. Quan, T. Kobayashi, and C. Lee: J. Microelectromech. Syst. 20 (2011) 1131.

14 S. B. Kim, H. Park, S. H. Kim, J. H. Park, and D. J. Kim: J. Microelectromech. Syst. 22 (2013) 26.

15 B. S. Lee, S. C. Lin, W. J. Wu, X. Y. Wang, P. Z. Chang, and C. K. Lee: J. Micromech. Microeng. 19 (2009) 065014.

16 T. Wang, T. Kobayashi, and C. K. Lee: Appl. Phys. Lett. 106 (2015) 013501.

17 Y. C. Shu and I. C. Lien: J. Micromech. Microeng. 16 (2006) 2429.

18 R. Elfrin, T. M. Kamel, M. Goedbloed, S. Matova, D. Hohlfeld, Y. V. Andel, and R. V. Schaijk: J. Micromech. Microeng. 19 (2009) 094005.

19 B. Yang, C. K. Lee, G. W. Ho, W. L. Ong, J. Q. Liu, and C. S. Yang: IEEE J. Microelectromech. Syst. 21 (2012) 776.

20 D. N. Shen, J. H. Park, J. H. Noh, S. Y. Choe, S. H. Kim, H. C. Wikle, and D. J. Kim: Sens. Actuators, A 154 (2009) 103.

21 J. Q. Liu, H. B. Fang, Z. Y. Xu, Z. H. Mao, X. C. Shen, D. Chen, H. Liao, and B. C. Cai: J. Microelectron. 39 (2008) 802.

22 A. Koka, Z. Zhou, and H. A. Sodana: Energy Environ. Sci. 7 (2014) 288.

23 B. S. Lee, S. C. Lin, W. J. Wu, X. Y. Wang, P. Z. Chang, and C. K. Lee: J. Micromech. Microeng. 19 (2009) 065014.

24 T. Kanda, M. K. Kurosawa, H. Yasu, and T. Higuchi: Sens. Actuators, A 89 (2001) 16.

25 S. B. Beeby, A. Blackburn, and N. M. White: J. Micromech. Microeng. 9 (1999) 218.

26 A. Lei, R. Xu, L. Borregaard, M. Guizzetti, and E. Thomsen: IEEE 24th Int. Conf. Micro Electro Mechanical Systems (MEMS) (2011) 125.

27 X. Y. Wang, C. Y. Lee, C. J. Peng, P. Y. Chen, and P. Z. Chang: Sens. Actuators, A 143 (2008) 469.

28 K. Tanaka, T. Konishi, M. Ide, and S. Sugiyama: J. Micromech. Microeng. 16 (2006) 815.

29 X. H. Xu and J. R. Chu: J. Micromech. Microeng. 18 (2008) 065001.

30 G. Tang, J. Liu, B. Yang, J. Luo, H. Liu, Y. Li, C.Yang, D. He, V. Dao, K. Tanaka, and S. Sugiyama: J. Micromech. Microeng. 22 (2012) 065017.

31 S. W. Bedell, K. Fogel, P. Lauro, D. Shahrjerdi, J. A. Ott, and D. Sadana: J. Phys. D: Appl. Phys. 46 (2013) 152002.

32 G. T. Hwang, H. Park, J. H. Lee, S. Oh, K. Park, M. Byun, H. Park, G. Ahn, C. K. Jeong, K. No, H. Kwon, S. G. Lee, B. Joung, and K. J. Lee: Adv. Mater. 26 (2014) 4880.

33 Y. J. Zhai, L. Mathew, R. Rao, D. W. Xu, and S. K. Banerjee: Nano Lett. 12 (2012) 5609.

34 D. H. Kim, J. Viventi, J. J. Amsden, J. L. Xiao, L. Vigeland, Y. S. Kim, J. A. Blanco, B. Panilaitis, E. S. Frechette, D. Contreras, D. L. Kaplan, F. G. Omenetto, Y. G. Huang, K. C. Hwang, M. R. Zakin, B. Litt, and J. A. Rogers: Nat. Mater. 9 (2010) 511.

35 K.-I. Park, S. Y. Lee, S. Kim, J. Chang, S. J. L. Kang, and K. J. Lee: Electrochem. Solid State Lett. 13 (2010) 57.

36 Y. Qi, N. T. Jafferis, K. Lyons, C. M. Lee, H. Ahmad, and M. C. McAlpine: Nano Lett. 10 (2010) 524.

37 Y. Qi, J. Kim, T. D. Nguyen, B. Lisko, P. K. Purohit, and M. C. McAlpine: Nano Lett. 11 (2011) 1331.

38 G. T. Hwang, J. Yang, S. H. Yang, H. Y. Lee, M. Lee, D. Y. Park, J. H. Han, S. J. Lee, C. K. Jeong, J. Kim, K. Park, and K. J. Lee: Adv. Energy Mater. 5 (2015) 1500051.

39 K. Park, J. H. Son, G. T. Hwang, C. K. Jeong, J. Ryu, M. Koo, I. Choi, S. H. Lee, M. Byun, Z. L. Wang, and K. J. Lee: Adv. Mater. 26 (2014) 2514.

40 E. E. Aktakka, R. L. Peterson, and K. Najafi: Transducer's 11 (Beijing, China) (2011) 1649.

41 G. Tang, B. Yang, J. Liu, B. Xu, H. Zhu, and C. Yang: Sens. Actuators, A 205 (2014) 150.

42 B. Yang, Y. B. Zhu, X. Z. Wang, J. Q. Liu, X. Chen, and C. S. Yang: Sens. Actuators, A 214 (2014) 88.

43 S. Roundy, P. K. Wright, and J. A. Rabaey: Comput. Commun. 26 (2003) 1131.

44 S. Roundy: J. Intell. Mater. Syst. Struct. 16 (2005) 809.

45 S. Roundy and P. K. Wright: Smart Mater. Struct. 13 (2004) 1131.

46 H. Bottner, J. Nurnus, and A. Gavrikov: J. Microelectromech. Syst. 13 (2004) 414.

47 K. Ikeda, H. Ishizuka, A. Sawada, and K. Urushiyama: Industrial Health 36 (1998) 197.

48 M. M. Frechin, S. B. Arino, and J. Fontaine: Proc. Inst. Mech. Eng. P. J. Automob. Eng. 218 (2004) 925.

49 G. Tang, B. Yang, C. Hou, G. Li, J. Liu, X. Chen, and C. Yang: Sci. Rep. 6 (2016) 38798. 
50 Z. L. Wang and W. Z. Wu: Angew. Chem. Int. Ed. 51 (2012) 11700.

51 L. Persano, C. Dagdeviren, Y. Su, Y. H. Zhang, S. Girardo, D. Pisignano, Y. G. Huang, and J. A. Rogers: Nat. Commun. 4 (2013) 1633.

52 S. Zhang, S. M. Lee, D. H. Kim, H. Y. Lee, and T. R. Shrout: Appl. Phys. Lett. 93 (2008) 122908.

53 O. Bilgen, M. A. Karami, D. J. Inman, and M. I. Friswell: Smart Mater. Struct. 20 (2011) 055024.

54 D. H. Kim, H. J. Shin, H. Lee, C. K. Jeong, H. Park, G. T. Hwang, H. Y. Lee, D. J. Joe, H. Han, S. H. Lee, J. Kim, B. Joung, and K. J. Lee: Adv. Funct. Mater. 27 (2017) 1700341.

55 H. G. Yeo, X. Ma, C. Rahn, and S. Trolier-McKinstry: Adv. Funct. Mater. 26 (2016) 5940.

56 Z. R. Yi, B. Yang, G. M. Li, J. Q. Liu, X. Chen, X. L. Wang, and C. S. Yang: Appl. Phys. Lett. 111 (2017) 013902.

57 R. Elfrink, T. M. Kamel, M. Goedbloed, S. Matova, D. Hohlfeld, Y. Andel, and R. van Schaijk: J. Micromech. Microeng. 19 (2009) 094005.

58 T. M. Kamel, R. Elfrink, M. Renaud, D. Hohlfeld, M. Goedbloed, C. de Nooijer, M. Jambunathan, and R. van Schaijk: J. Micromech. Microeng. 20 (2010) 105023.

59 E. E. Aktakka, R. L. Peterson, and K. Najafi: Electron Devices Meeting (IEDM), 2010 IEEE International (2010) p. 31 .

60 E. K. Reilly, F. Burghardt, R. Fain, and P. Wright: Smart. Mater. Struct. 20 (2011) 12.

61 P. Janphuang, R. Lockhart, N. Uffer, D. Briand, and N. F. de Rooij: Sens. Actuators, A 210 (2014) 1.

62 B. Yang, Y. B. Zhu, X. Z. Wang, J. Q. Liu, and C. S. Yang: Sens. Mater. 26 (2014) 591. 